methods of the Nancy School, confining suggestions to the functions of the organism, will admit that he has ever seen a result in any sense injurious to the patient. Consider the vast number of patients which this statement includes!

One argument agaiust the use of hypnotism I cannot leave unmentioned. It is, that in using it a phy. sician, simply because this thing has in the past been largely in the hands of quacks, might injure his practice or hurt his standing. This needs only one word of reply : 'To put it mildly, it is the argument of a man without courage. Nevertheless, the timid physician, who believes in hypnotism, doubtless finds reason to be thankful for the fact that to-day hypnotic suggestion stands firmly upon scientific ground, and that it is practised abroad by men whose judgment is ripe and whose medical attainments occupy the first rank.

Personally, I should feel that I were doing wrong, and were disobeying duty, if I were unwilling to apply hypnotic suggestion wherever I saw it were likely to aid the patient.

And this is the outcome of my experience in this branch of therapeutics.

\section{TRICUSPID STENOSIS, WI'TH THE REPORT OF A CASE AND SPECIMEN.?}

ISY FREDEHICK C. SHATTUCK, M.1).,

Jackson I'rofessor of Clinical Medicine in Harvard University, Visiting 1'hysician to the M/assachusetts General Hospital, etc.

I1. G., forty-three years old, seamstress and housekeeper, entered the House of the Good Samaritan for the first time February 19, 1886. Her father died of "liver complaint that turned to black vomit" (cirrho. sis ?) at forty. Her habits were markedly alcoholic for a period, but she is now a total abstainer. She had scarlet fever when eleven. In 1871 she had a cold that "settled in her legs," the muscles rather than the joints, and was laid up a fortnight. No other history suggesting rheumatism was obtained. Soon after that, she began to suffer from attacks of asthma, and could not sleep on feathers; but nothing like spasmodic asthma was ever observed by me. She could not lie on the right side on account of pain in the hepatic region. In 1878 or 1879 she went to the Outraptient Department of the City Hospital, on account of a very bad cough, and was admitted to the ward, remaining ten days. At this time she was told that her heart was affected. In May, 1881, she entered again for ten

- days. In July, 1881, she was delivered of a child at the Boston Lying-in Hospital, resuming work in two weeks. In 1886 the child was alive and well. In September, 1883, suffering from "brouchitis and asthma," she went to Savannah. There she became worse, and her abdomen swelled for the first time. She was treated in hospital, and relieved of her dropsy. Up to that time the catamenia had been regular, but from that date they became irregular: absent since August, 1885. In subsequent years they recurred a few times. After her return from the South in 1883 she again became dropsical, and re-entered the City Hospital for fourteen days. In the winter of 1884 she returned to the hospital; and again, for cough, in the summer of 1885. In October, 1885, the legs as well as the abdomen were swelled, and she passed three months at

1 Read before the Boston Society for Medical Obsorvation, December 1,1890 . the City Hospital, was transferred to St. Luke's, and returned to the City Hospital for three weeks. While at St. Luke's she became somewhat jaundiced. Ever since 1879 she has suffered from gradually increasing dyspnca, and at times orthopnoca. Bowels have been free even to diarrhoca.

Physical Examination. - Slight icteric hue of the conjunctivæ. General integument darkish in color. No marked cyanosis. Respiration labored. Jugulars distended. Cardiac area prominent. Marked undulation of the cardiac, epigastric and hepatic regions, beginning at the second rib at the left of the sternum. No distension of the superficial thoracic or abdominal veins. Pulsation is felt all over the cardiac, epigastric, and hepatic regions. The hand placed over the liver is raised synchronously with the apex-beat. 'The impulse is distinct in the fifth space outside the mammillary line. The area of cardiac dulness is somewhat increased, especially to the right. Over euch of the aortic, mitral and tricuspid orifices, double murmurs are to be heard. The aortic systolic is transmitted upward into the great ressels; the diastolic downward. The systolic and pre-systolic murmurs in the tricuspid area can be differentiated from those in the mitral area, their qualities being quite different, and the tricuspid pre-systolic distinctly musical. Moderate ascites. Hepatic thatness begins at the fourth rib in the right front, and the organ can be felt through the ascitic fluid nearly as low as the navel. The size of the spleen is doubtful. The lungs are somewhat compressed by the ascent of the diaphragm, otherwise negative. The urine, 1,200 c. c. in twenty-four hours, is one of passive congestion. The girth is thirty-eight inches.

After careful study of the case I was couvinced that tricuspid stenosis was present in addition to the other more obvious pathological changes.

March 7th, the abdomen was tapped with great relief. May 27th, she was discharged, free from dropsy and fairly comfortable; with a girth of thirty inches. November 27 th, she re-entered, having worked only about two weeks since disclarge. Sho was in much the same condition as at her first admission to the Samaritan, but jugular pulsation was now marked. Under treatment the dropsy disappeured, as did also the presystolic tricuspid murmur, and 1 never heard this again. The other murmurs remained much the same. May 24, 1887, she was discliarged, having passed three of the intervening months at the Convalescent Branch of the Samaritan. March 15, 1888, she reentered, having worked on a power sewing-machine up to three weeks previously, and " has felt better than for fifteen years." Orthopuca with deficient resonance, and moist râles over both backs, especially at the bases, were noted. The other signs were much as before. No tricuspid pre-systolic murmur was heard. May 22d, she was again discharged. February 4, 1890, after an interval of nearly two years, during which she worked most of the time, she entered the Samaritan for the last time. The most marked change in the physical signs was a diminution in the size of the liver, which could still, however, be felt, and a systolic retraction in the apex region, leuding to the diagnosis of adherent pericardium. In spite of treatment, including paracentesis abdominis, the use of Southey's tubes in the legs, and leeching over the liver, the urine remained scanty, dropsy increased, and May $3 \mathrm{~d}$ she died. The clinical diagnosis was written down as follows: mitral and tricuspid stenosis und regurgitation; aortic 
regurgitation and stenosis or roughening; adherent pericardium; hepatic cirrhosis; slight interstitial nephritis.

Autopsy, by Dr. Fitz, twenty-nine hours after death. Abdomen moderately distended. Legs and feet œdem. atous. Head not opened. Pericardium obliterated by old adhesions. Heart moderately enlarged. Right side distended, with differentiated clot. Aortic valve incompetent. Pulmonic valves hold water. Aortic crescents thickened, shortened, adherent to such a degree that the opening would barely admit a lead pencil. The edge of the opening showed fine white excrescences. 'The mitral orifice would not permit the passage of the little finger. 'The curtains were thickened, shortened, adherent. The auricular surfaces slightly roughened; the tendons shortened, thickened, adherent. 'Tricuspid orifice admits but two finger-tips; curtains aud tendons shortened and thickened. Edge of curtains showed delicate vegetatious. 'The pulmonary crescents showed delicate translucent vegetations along the line of apposition. 'Two of the crescents were slightly adherent. 'The left ventricle was not evidently hypertrophied or dilated; the left auricle dilated; the endocardium thickened. 'The right ventricle hypertrophied; the right auricle moderately dilated. The aorta showed extensive thick, white patches, and u circumscribed dilatation as large as a walnut at the beginning of the arch. 'The pulmonic artery was dilated, its inner surface showing superificial, opaque, yellow patches. The pleural cavities were obliterated by fibrous adhesions. The lungs were slightly injected and wdematous. 'The abdomen contained a quart of clear, yellow fluid. Spleen was reduced in size, perhaps onethird, dense, dark-colored; trabeculw distinct. Kidneys were diminished in size, dense, the capsule rather more adherent than usual; on section, of a dark-gray color. Nothing abnormal in the appdarance of the bladder and the uterus. Ovaries atrophied. The liver was diminished in size, perhaps one-third, dense, the surface irregularly roughened, peritoneum thickened. On section occasional bands of fibrous tissue traversed the surface. Atrophied lobules, with pigmeuted central portions, were occasionally seen, especially at the periphery. 'The stomach showed extensive pigmentation of a bluish-slate color. The mucous membrane of the intestines, especially of the colon, was odematous.

Pathological diagnosis: chronic adhesive pericarditis; chronic valvular endocarditis of all the valves; aneurism of the aorta; chronic adhesive pleurisy; ascites; chronic congestion of spleen and kiduey ; chronic interstitial hepatitis with slight nutmeg atrophy; chronic catarrhal gastritis; odema of the intestines.

Summary. - A woman, long addicted to alcohol, is quite healthy in the main up to the age of thirty-five. Cough then leads to the discovery of a cardiac lesion; and during the remaining twelve years of her life she thirteen times requires hospital treatment, at first for short, later for longer periods, between times earning her support by machine-sewing by steam power. 'The symptoms at first are indicative of compensatory disturbance. Later, ascites and slight icterus with marked hepatic enlargement are superadded. Under treatment and rest she recovers several times from a seemingly desperate condition. For nearly two years before her death, while the subject of stenosis and regurgitation at the aortic, mitral and tricuspid orifices, hepatic cirrhosis, and probably of pleural and pericardial obliter- ation, she is relatively comfortable, requires no medical advice and supports herself.

Remarks.- 'Tricuspid stenosis as an acquired lesion is of not very great rarity, is usually of rheumatic origin, affects females far more than males, is always combined with a similar condition of the mitral valve, almost always with the clear evidences of endocarditis of the aortic valves, even if this is not far enough aclvanced to have produced stenosis or Jeakage. Literature contains only one or two references to uncombined tricuspid stenosis. One is reported by Duroziez, ${ }^{2}$ another by 'Torres Homem, of Rio. ${ }^{8}$ Very important contributions to our knowledge of the subject have been made by Dr. Bedford Fenwick, ${ }^{4}$ who collected and analyzed seventy cases. I have found nineteen other cases published since his paper appeared, which bear out in the main his conclusions, though the proportion of males is rather larger, and the average age at death less than in his cases. The diagnosis of the tricuspid lesion was made during life in less than half a dozen of the eighty-nine reported cases, and I find no American case recorded with diaguosis intra vitam, though I am informed that Dr. Delano of this city has twice made the diagnosis, and found it confirmed by the autopsy. It is well known that a high degree of mitral stenosis may exist without any constant murmur, to say the least. In like manner the tricuspid lesion may be silent; or, if it gives rise to a murmur, the souffle may be indistinguishable from that attributable to the mitral orifice. In my case, during a limited period of time, two distinctly pre-systolic murmurs could be heard, one at each apex, beside the diastolic souftle of aortic incompetency. Whether a pre-systolic tricuspid souflle can be heard or not, tricuspid stenosis can be pretty safely diagnosticated if the patient is a female with rheumatic history, has mitral stenosis, perhaps also aortic disease, and presents the evidences of prolonged or recurrent venous stasis of greater or less degree. Fenwick explains the fact that tricuspid stenosis is so nearly confined to the female sex, more so, indeed, than mitral stenosis, as follows: In women the life work is less onerous; the action of the heart is less powerful. Back pressure is therefore slighter, and consequently the valve disturbance less than in men. In men, muscle-straining labor, greater compensatory hypertrophy, and more powerful cardiac action, prevent the inflamed edges of the valves from adhering together. (For a more complete explanation consult his article.)

The insidious character of the endocurditis in $\mathrm{my}$ case, seems worthy of passing mention. The attack of scarlet fever at eleven years of age may have been its origin, inasmuch as any history of the articular form of rheumatism was quite lacking. The mitral valve was probably the first to suffer. 'The changes in the aortic were rather higher in degree than those in the tricuspid valve, but not therefore necessarily older. The pulmonic valves were relatively slightly affected, and were probably the last to be attacked. The adhesive pleurisy and pericarditis were also insidious, and probably gradual in their progress. The patient never had any fever while she was under my observation, having a subnormal rather than an elevated temperature.

Finally, the tolerance of the patient of such wide-

: L'Union Medicalo, December 23, 25, 1883.

- Rov. de Cursos de Rlo do Jnuciro, $1,135,1884$

- Iransactions of the Loudon Pathologioal Society, 1881, p. 42 ; 1882, p. 64; 1883, p. 30; Aler) Journal, cxi, p. $2(17$. 
spread and serious disease seems noteworthy. Cirrhosis with great enlargement of the liver, some of which was doubtless due to passive congestion, was unmistakable four years before her death.

As for the valvular lesions, their slow development probably explains in a large measure their toleration. It is remarkable that compensation should have been established with so little hypertrophy. 'The left ven: tricle was not markedly dilated or hypertrophied, al. though the aortic orifice was incompetent and highly stenosed. It was in the right ventricle that hypertrophy was most marked, while dilutation was most conspicuous in the right auricle.

\section{RECEN'T PROGRESS IN PUBLIC HYGIENE.'}

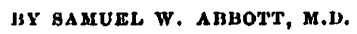

\section{VITAL STATIBTICS.}

'TuE science of vital statistics forms the basis of very much of our accurate knowledge with reference to the prevalence of disease, so far as it is affected by varying conditions of climate, geographical distribution, age, sex, occupation, and seasons of the year. Especially is this true with reference to those diseases which may be termed preventable, and which pertain to the pro. vince of public hygiene.

Dr. Longstaff ${ }^{8}$ has extracted from the Census Reports of different countries, and from the Registrar General's Returns a wealth of material which is especially valuable to the physician and to the sanitarian.

The following table is selected as showing how important and valuable material may be obtained from the wilderness of figures presented in the Returns of the Registrur General's Office : -

RIBE OR FALL IN THK DEATH-HATHS,

Jer million persons living in England and Wales, from various causes or groups of causes. Averayes of quinquennium 1876-1879, compared with averajes of guinquennium 1850-1854.

RIsIeN, per million living :

Lung disosses.

$\cdot \quad \cdot \quad \cdot \quad \cdot 1,213$

Brain diseases, except convulsions . . . . 378

Kidney diseases . . • . . . . . 229

Cancer . . • . . . . . . . 191

Dlphtheris and croup . • . . • . 69

Tubes mesenterica . . . . . . . . 65

Whooping-cuugh . . . . . . . . . 45

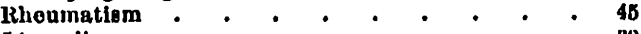

Liver diseases • • • • • • • •

Fallok, per mtllion living :

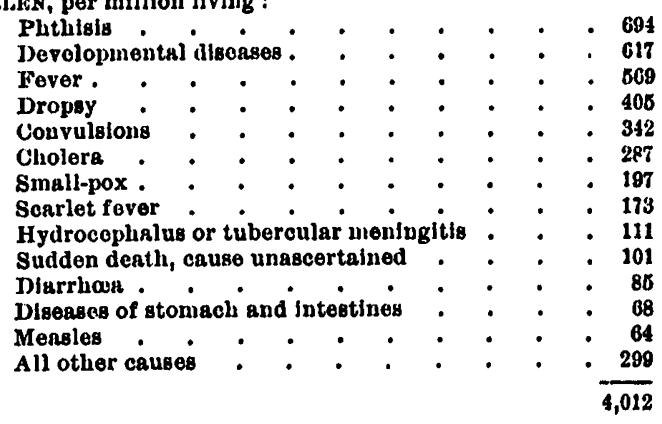

Balance, a fall of

. 1,048

This table is fully discussed by Dr. Longstaff. A brief quotation indicates its value :

1 Concluded from page 288.

- Studiog In Statstog by George Blundell Longetatr, M.A., M.B., F.R.U.P., otc. I.ondon. 1891 .
"In the first place it will be noticed that six so-called 'zymotic diseases,' namely fever, cholera, small-pox, scarlet-fever, diarrhoa, and measles, between them contribute a fall of 1,375 deaths per million, against which there is a set-off of 114 , being the rise under the heads of diphtheria, croup, and whooping.cough, leaving $a$ net fall of 1,261 deaths per million from the principal zymotic diseases; but as the total fall from all causes is 1,049 , it is evident that the deaths from non-zymotic diseases must have risen 212 per million.

"The per centage fall in the death-rate from 'fever" (chiefly ty phus and typhoid) is very remurkable, being no less than 57 per cent. for each sex, the fall being spread over all ages, though old people gain most; the number of 'lives saved' is no less than 6,188 males and 6,510 females yearly; the salvage being yreatest under five years of age, but very considerable at each age below 75. It seems impossible to dissociate this great saving of life from the operation of the Public Health Acts. .. . The fall in the death-rate from fever is without doubt the great triumph of the sanitary reformers. 'Typhus has been driven out from place after place by measures taken to check overcrowding and want of ventilation, until it now lingers only in the lowest quarters of a few large towns. Things are not perfect yet, far from it; but they were once much worse, and that not long ago. On the other hand, measures directed to improve drainage and water-supply have been most successful in restraining enteric fever within comparatively narrow limits."

Diphtheria. - Dr. Longstaff also presents the results of his researches as to the prevaleuce of diphtheria, geographically, in the different parts of England and Wales, and also for three different periods of time, $1855-60,1861-70$, and $1871-80$. In general he found that the mortality of rural districts was greater than that of cities, in the following ratio, taking 1,000 as the mortality of the densely settled districts :

Mortality from diphtheria of dense distriots . . . . 1,000

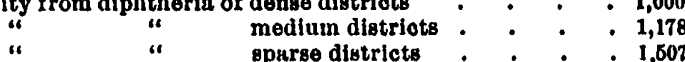

"The practical deduction suggested by these facts is, that the cause, or causes, of diphtheria should not be sought for primarily in any higher development of civilization, such as sewers, but rather in some condition associated with a more primitive mode of life. Again, privies and ash-pits can hardly be important agents in breeding or disseminating the disease, or wo should expect to find it exceptionally prevulent in those towns where such nuisances reach their worst, whereas the contrary is the case. On the other hand, low vegetable organisms developed in damp dwellings would perhaps fit in with the facts that 1 have brought forward, or again, some evil special to wells or other primitive sources of wuter-supply."

The author also suggests that the comparative pathology of the domestic animals affords a suggestive field for research, with reference to the greater prevalence of diphtheria in the rural districts.

In the Statistical Reports of the Italian Government ${ }^{\circ}$ are to be found many admirable summaries of the comparative prevalence of disease in different countries, from which the following table is condensed :

- Statistlca delle Cause Delle Morti, confronti Internazlona If. Roma, 1890. 